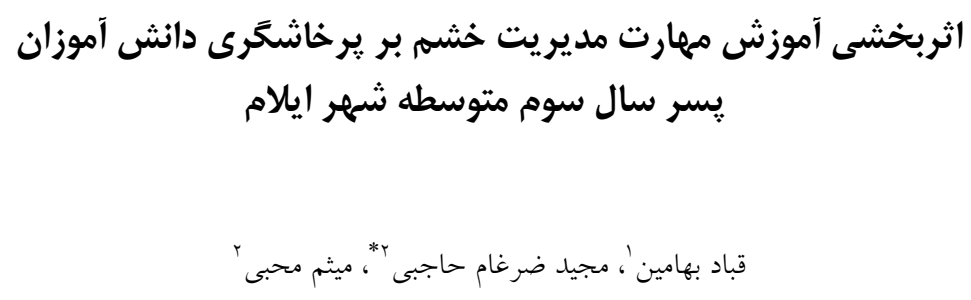

ا) كروه رولن شناسى، دانشكده روانغ شناسى، دلنشكاه بيام نزر، تهرانغ، إيران

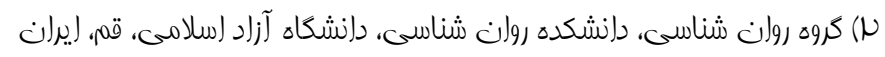

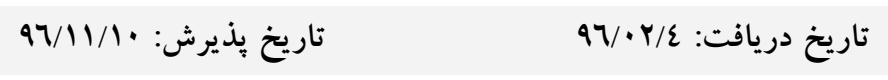

مقدمه: هدف از اين يزوهش بررسى اثربخشى آموزش مهارت هاى مديريت خشم بر كاهش بِرخاشكَى دانش آموزان بِسر سال سوم متوسطه شهر ايلام مى باشد.

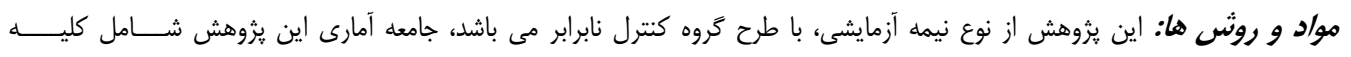

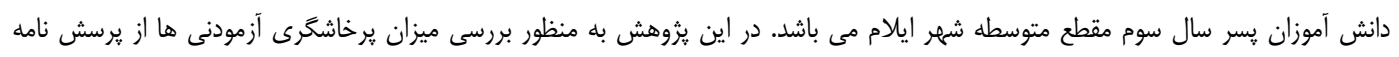

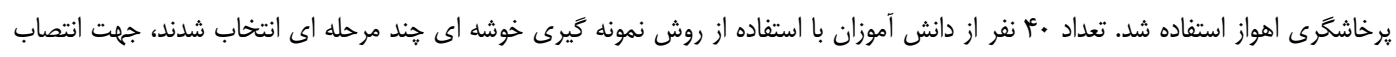

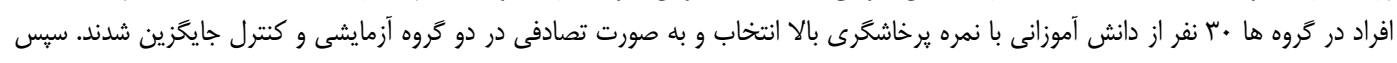

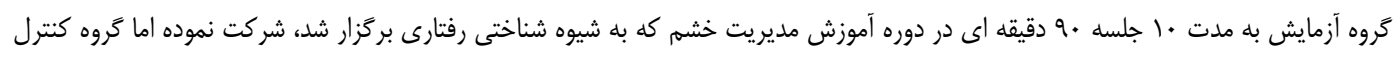
آموزشى دريافت نكردند.

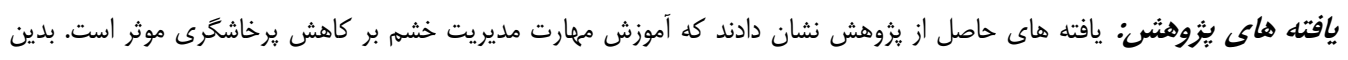

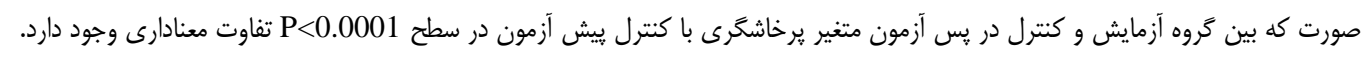

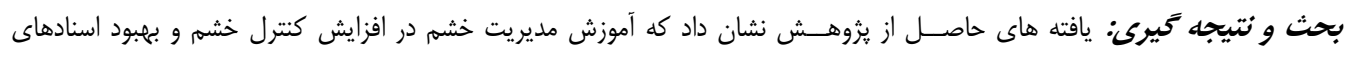

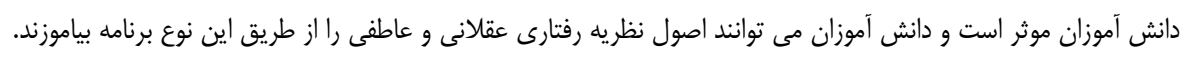

وازه هاى كليدى: مهارت هاى مديريت خشه، يرخاشكَى، دانش آموزان، مقطع متوسطه

* نويسنده مسئول: كروه روان شناسى، دانشكده روان شناسى، دانشكاه آزاد اسلامى، قم، ايران

Email: Psychologyclinical993@yahoo.com

Copyright $\odot 2018$ Journal of Ilam University of Medical Science. This is an open-access article distributed under the terms of the Creative Commons Attribution international 4.0 International License (https://creativecommons.org/licenses/by-nc/4.0/) which permits copy and redistribute the material, in any medium or format, provided the original work is properly cited. 
خشم، افزون بر ناراحتى شخصى، اختلال در سلامت

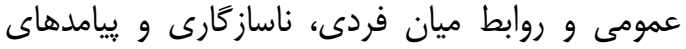

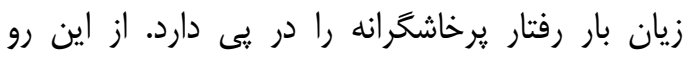

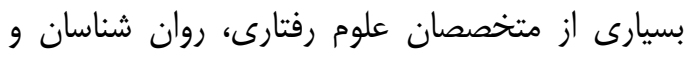

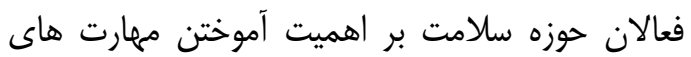

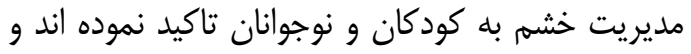

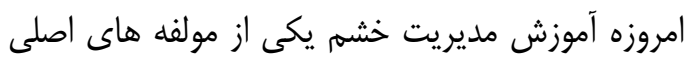

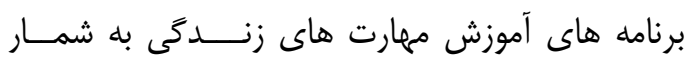

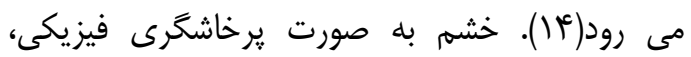
يرخاشكَى كلامى، خصومت، مخالفت، انتقاد، احساس رنجش، بارها درباره جيزى حرف زدن، دورى و اجتناب إناب

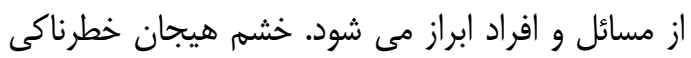

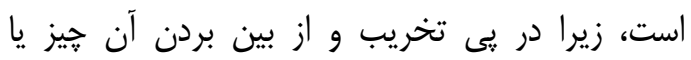

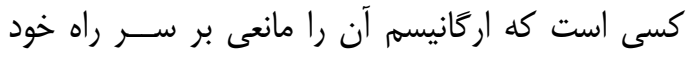

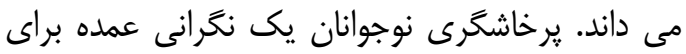

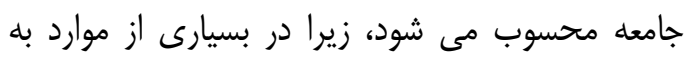

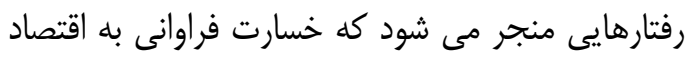
كشورها تحميل مى كند و رفتارهاى ضداجتماعى و وناف

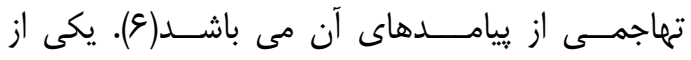

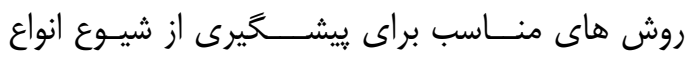

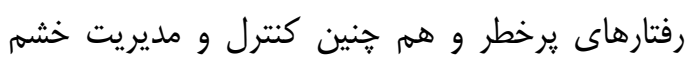
استفاده و آموزش مهارت هاى زندكى است. اصطاح

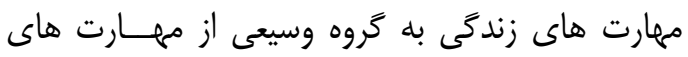

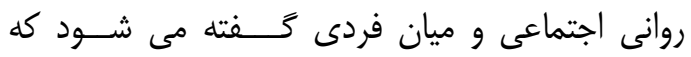

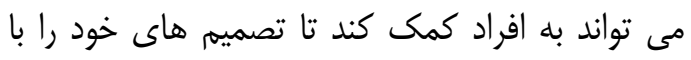
آكاهى اتخاذ كنند، به طور موثر ارتباط برقرار كنند،

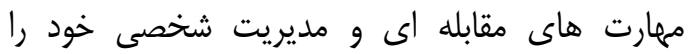
كسترش دهد و زندگى سالم و بارور داشته باشد(V). يكى از اين مهارت ها توانايى مقابله با هيجانات

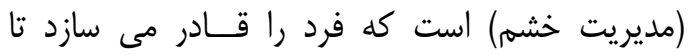
هيجان ها را در خود و ديخران تشخيص دهد نحوه

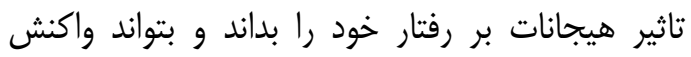
مناسبى به هيجان هاى مختلف نشان دهد(1). مطالعات طولى به طور مستمر نشان داده اند كه نوجوانانى كه مهارت هاى لازم جهت كنترل خشم را ندارند و خشم لهم

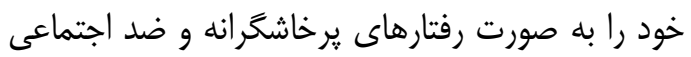

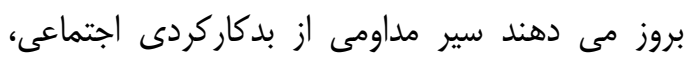

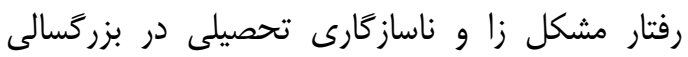

خشم يك هيجان يِيجيده و حيرت انكَيز است و

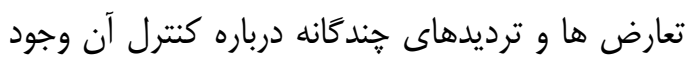

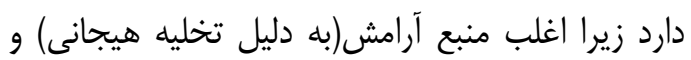

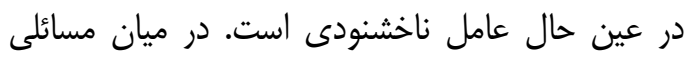

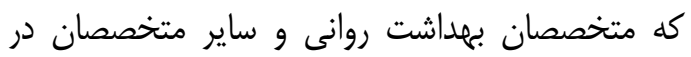
محيط هاى سازمانى يا مراكز درمان سريايى با آن هان آنائ مواجه مى شوند خشم مزمن و رفتار يرخاشخرانه مكرر

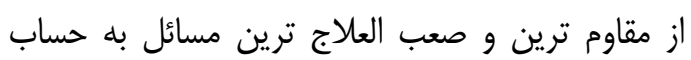

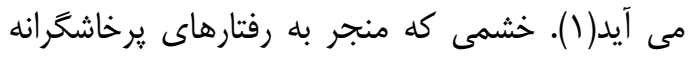

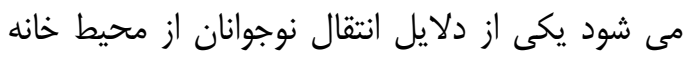

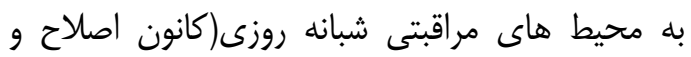

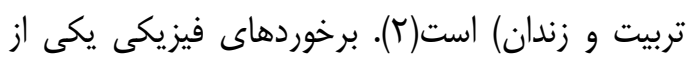

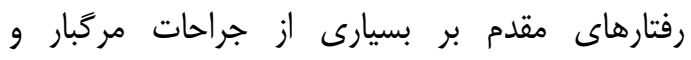
غيرمركبار است. متاسفانه برخوردهاى فيزيكى كهاري نتيجه عدم كنترل خشم و يرخاشكَرى هستند در بين

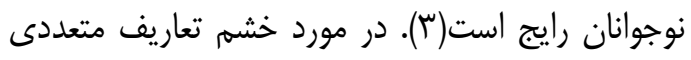

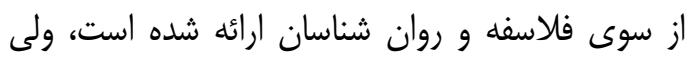
در تمام آن ها مى توان دو نكته مشترى را مشاهده

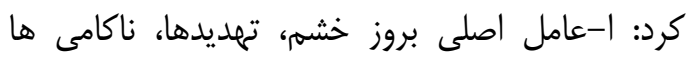

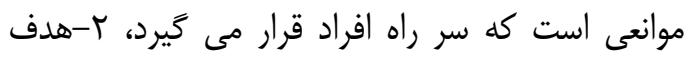

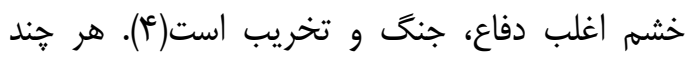
ساختار خشم مشتر كاتى با يرخاشگرى و خصومت دارد

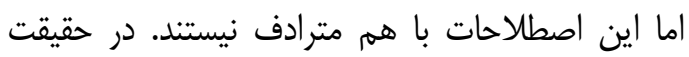
خشم يك هيجان، خصومت، يك نخر ش و يرخاشكَرى

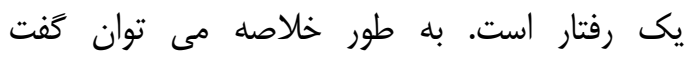
خصومت به عناصر شناختى يا بازخوردها نسبت داده

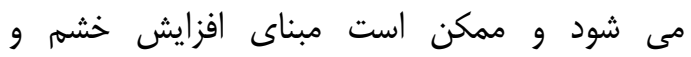

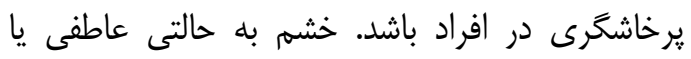

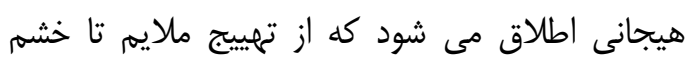

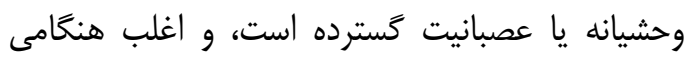

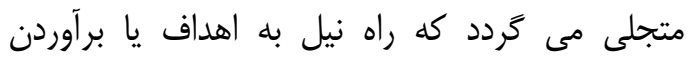

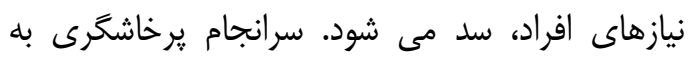

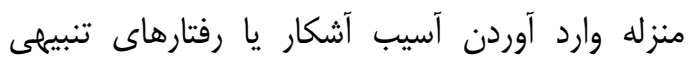
مستقيه به ساير افراد يا اشياء تعريف مى شود. با توجه أنهار به اين نكته كه خشم هيجانى ارضاء كننده و در عين

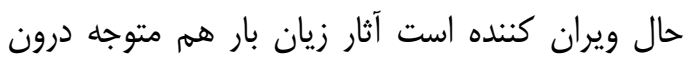
فرد و هم متوجه بيرون اوست. لذا ناتوانى در مديريت 
كه آموزش كنترل خشم بر يرخاشكَى دانش آموزان

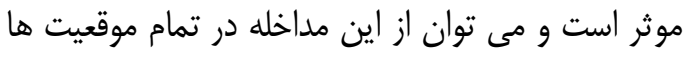

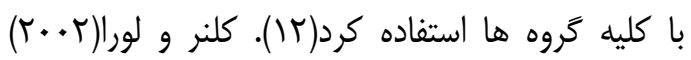

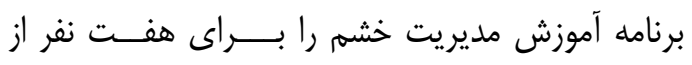
دانش آموزان يك مدرسه روزانه كه از لحاظ هيته ريجانى

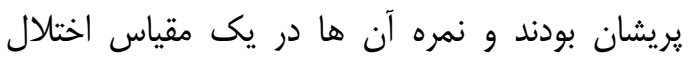
سلوى در دامنه بالينى قرار داشت اجرا كردند و اثرات

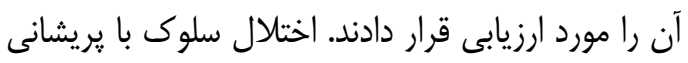

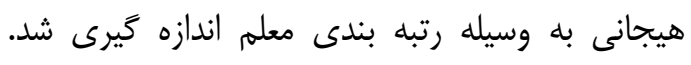

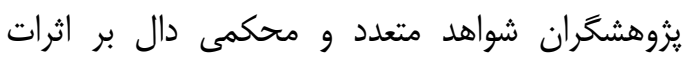

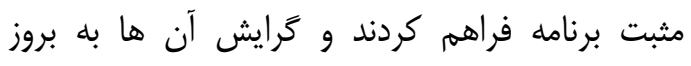
يرخاشخرى فيزيكى كاهش يافت و مورت معلمين و والدين

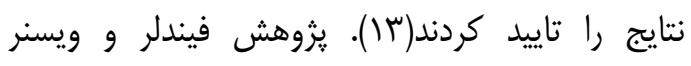

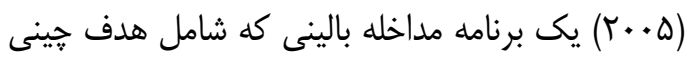

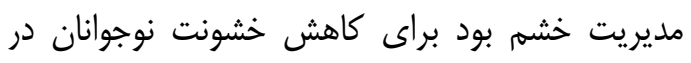

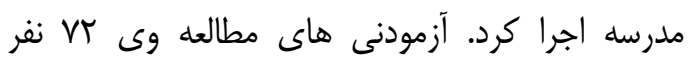

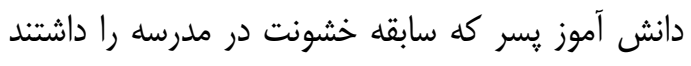

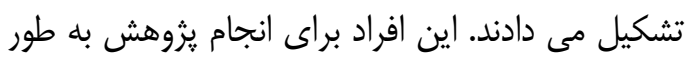

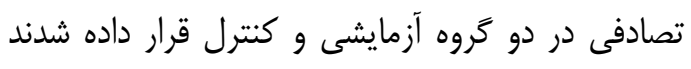

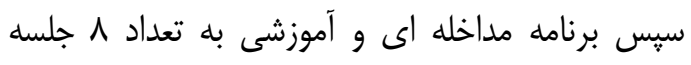

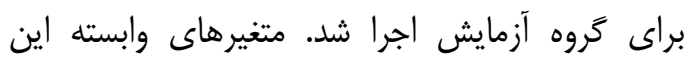

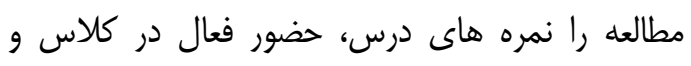

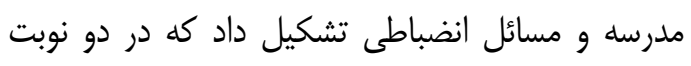

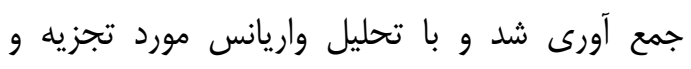

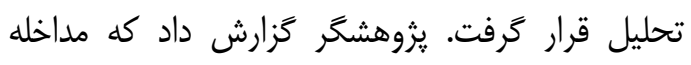

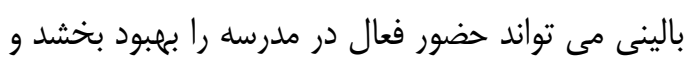

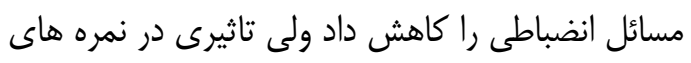

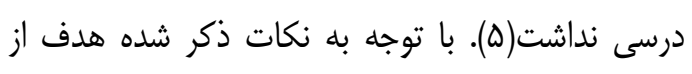

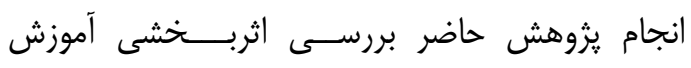

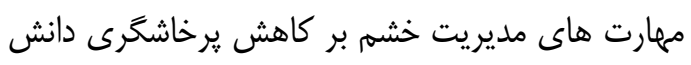
آموزان يسر سال سوم متوسطه شهر ايلام مى باشد.

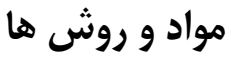

طرح يزوهش، نيمه آزمايشى با گروه كترل نابرابر

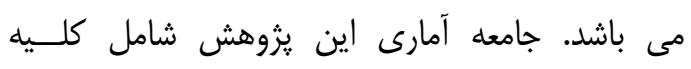
دانش آموزان يسر سال سوم مقطع متوسطه شهر ايلام

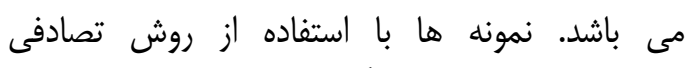

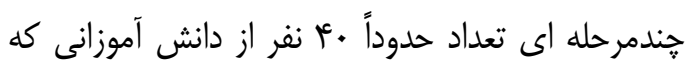

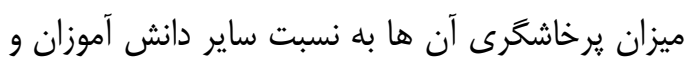

براى آن ها ييش بينى مى شود(9). رابينز(19AV) متذكر

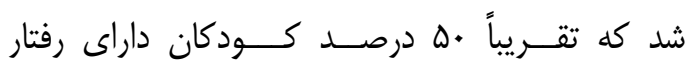

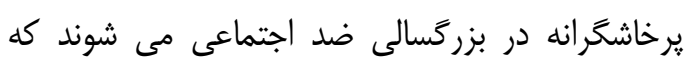

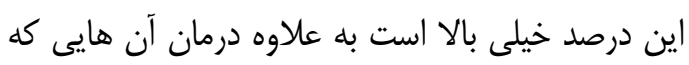

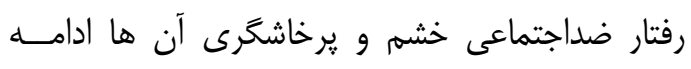

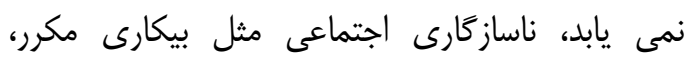

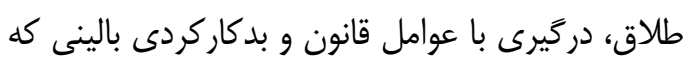

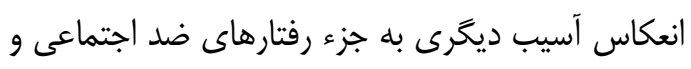

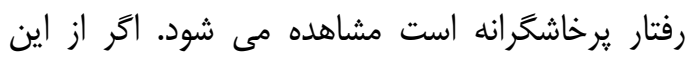

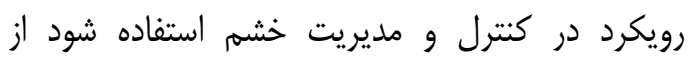

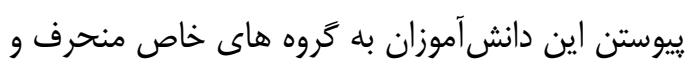

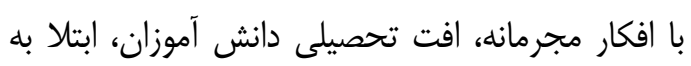

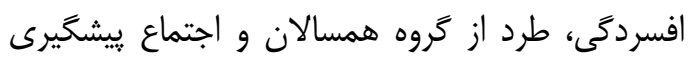

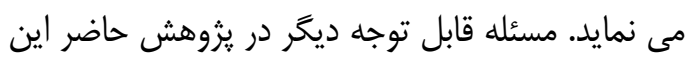

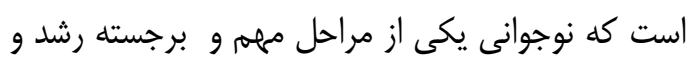

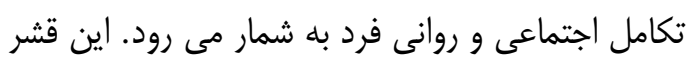

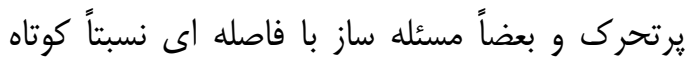

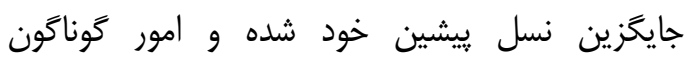

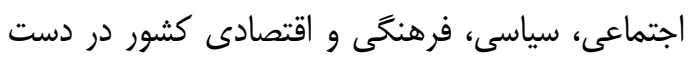

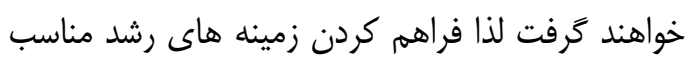

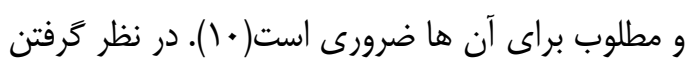

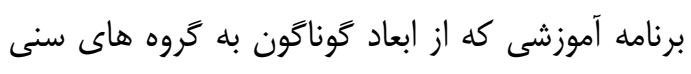

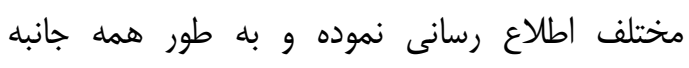
كاهش خشم را موجب گردد ضرورى و مفــيد به نظر

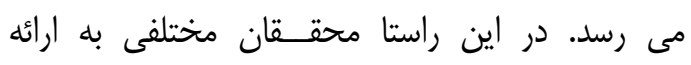

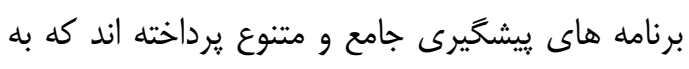

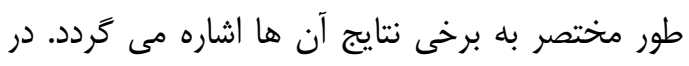

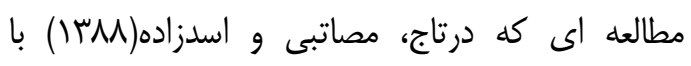

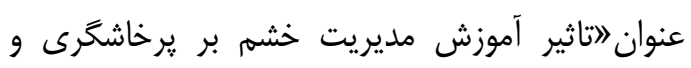

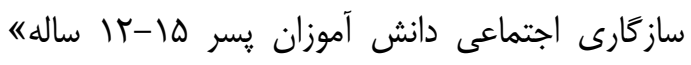

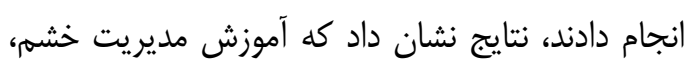

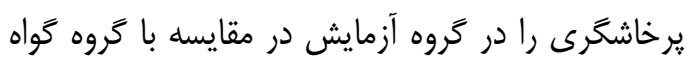
كاهش و ساز كارى اجتماعى آن ها را افزايش داده داده است

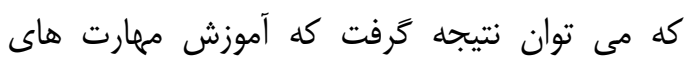

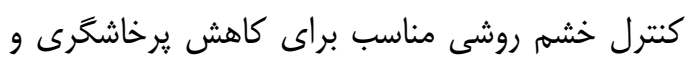

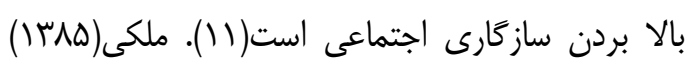

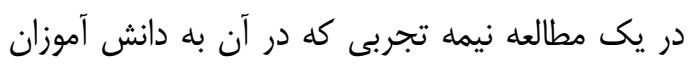

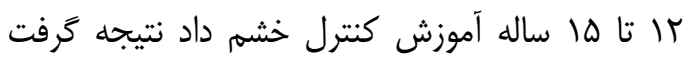


اهــواز از يرسـش نامه هاى ملاك شامل مقياس

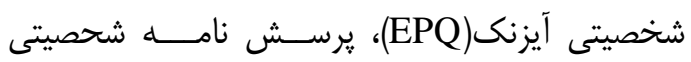

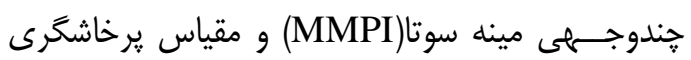

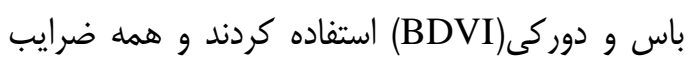
همبستخى بله دست آمده را در سـ طح

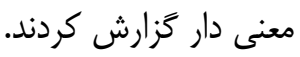

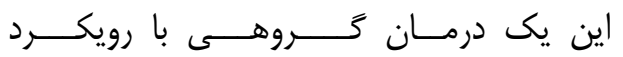

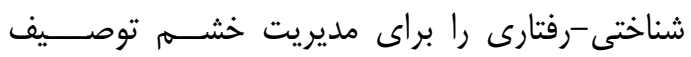

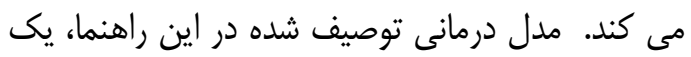

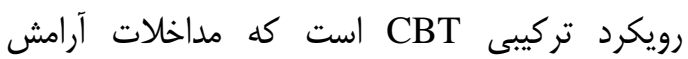

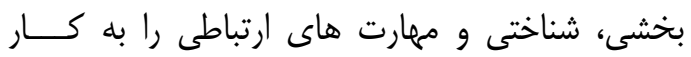

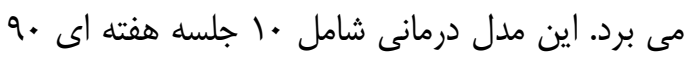
دقيقه اى است. لازم به ذكر است كه محتواى جلسات اين برنامه از منابع مرتبط و با پشتوانه يثوهشى بودها

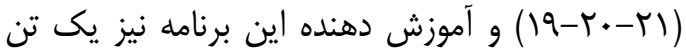

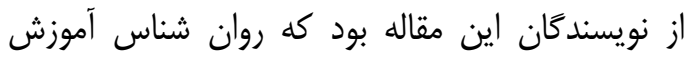
ديده در زمينه آموزش مديريت خشم است مقان و به به عنوان

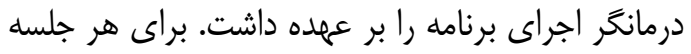
تكاليفى در مورد مسائل مطرح شده در جلسه در نظر بران

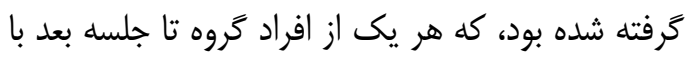

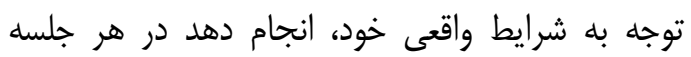
ضمن دريافت بازخورد از جلسه قبل، تكاليف جلسه قبل

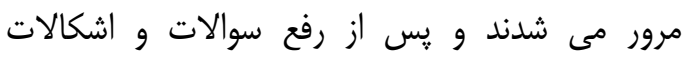

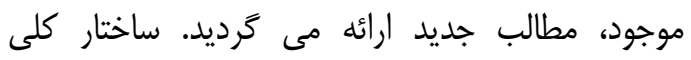
جلسات آموزش مديريت خشم عبارت است ازئ ازئ

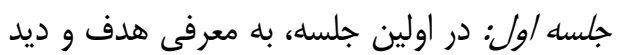

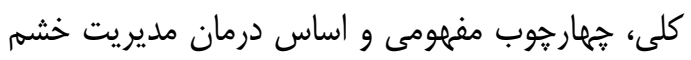

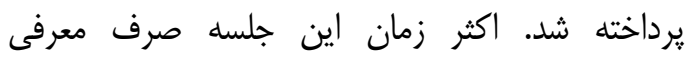

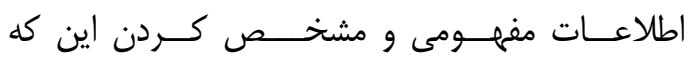

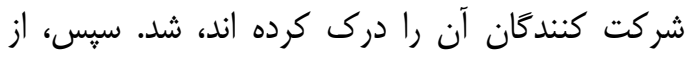

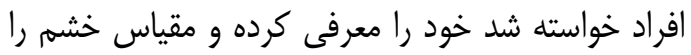

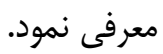

جلسه دوم: نكات مطرح شده در اين جلسه شامل:

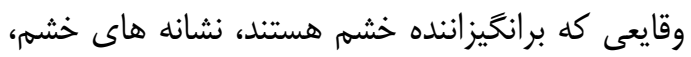
توضيح دادن روش وارسى تكاليف خانهوقايعى كه برانگيزنده خشه هستند. زمانى كه عصبانى مى شى شويد

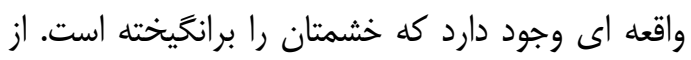

هم جنين بر اساس نقطه برش يرسش نامه پرخاشكَى

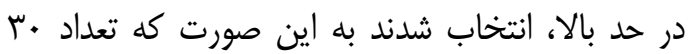

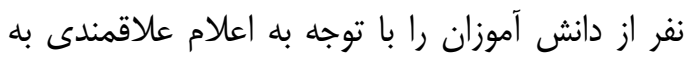

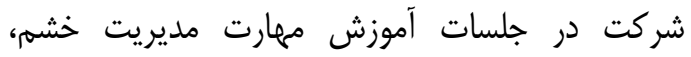

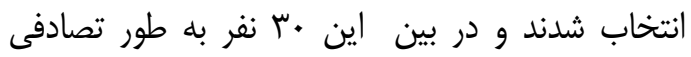

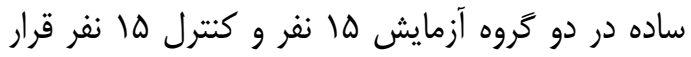
كرفتند. در اين يزوهش به منظور اندازه كَيرى يرخاشكرى و مولفه هاى آن از يرسش نامه يرخاشكرى استفاده

برسش نامه برخاشكرى (AGQ): : برسش نامه

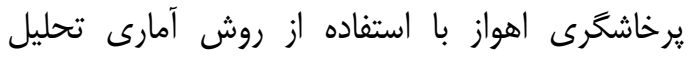

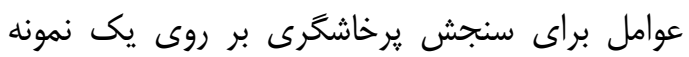

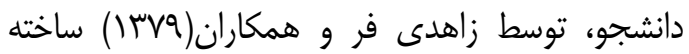

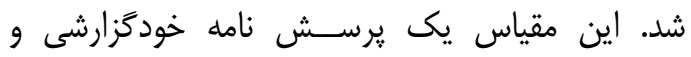

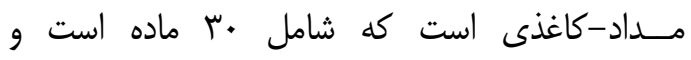

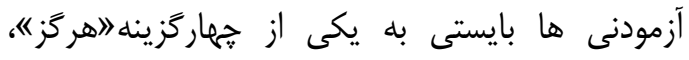

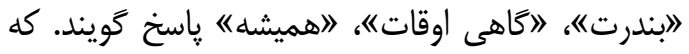

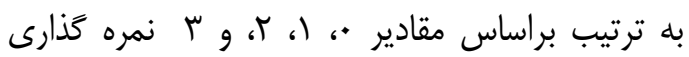

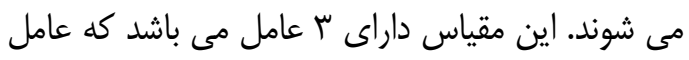

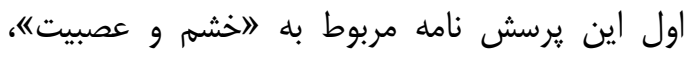

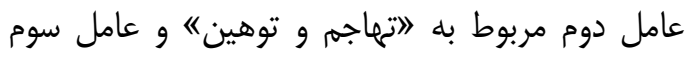

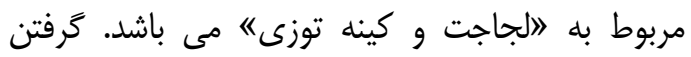

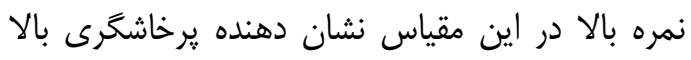

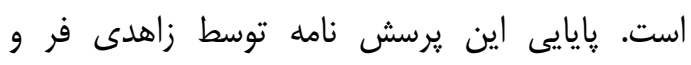

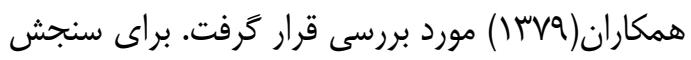

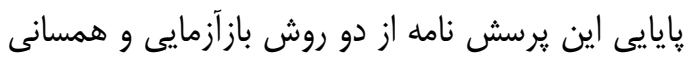

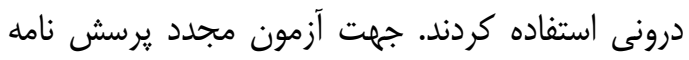

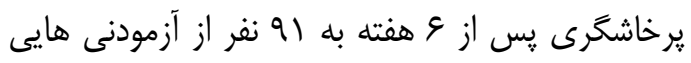

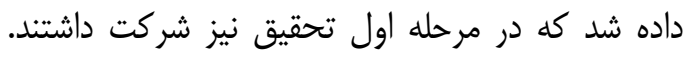

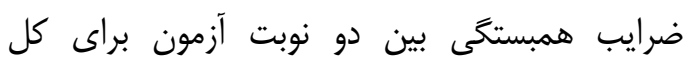

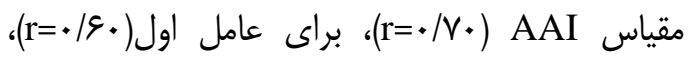

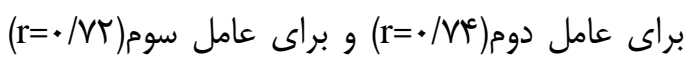
بود. هم جنين بر اساس نتايج حاصله ضرايب آلفاى

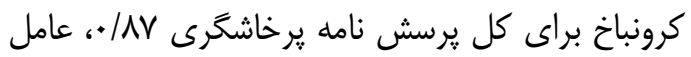

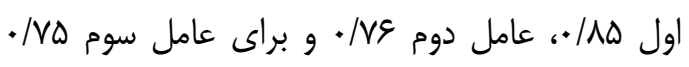

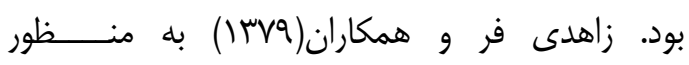

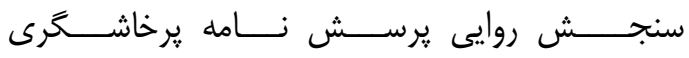


توجه به تعاهلاتى كه با والدين و خانواده اى كه در آن يرورش يافته اند به دست آورند. جلسه نهمز: اقدامات صورت كرفته در اين جلسه عبارت بودند از: مرور جلسه قبلى، تقويت كردن مفاهيم ياد گرفته شده، در اين جلسه ، مفاهيم اساسى مديريت خشم كه معرفى شده بودند، مرور و خلاصه مى شوند. توجه ويزه اى بايد به روشن نمودن و تقويت كردن لقدان

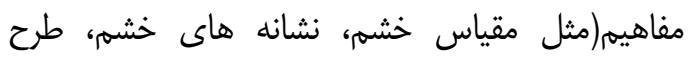

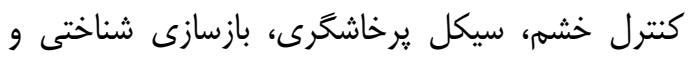

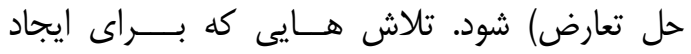

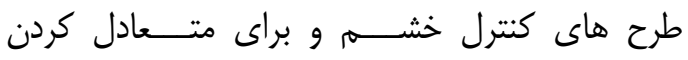

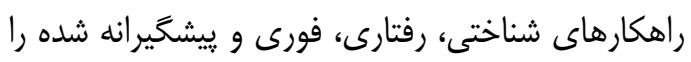

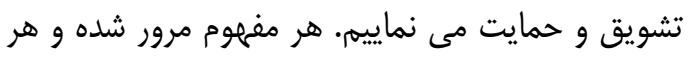

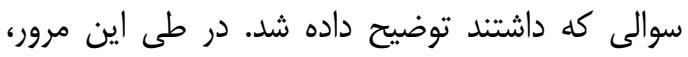
بحث تشويق شده و درخواست خواهد شد كه دركشان از مفاهيم مديريت خشم را توصيف كنند. جلسه دهمز در جلسه بايانى اقدامات زير صورت گرفت: مرور هر طرح كنترل خشه، براى متعادل كردن راهكارهاى رفتارى، شناختى، فورى و ييشخيرانه، ارائه

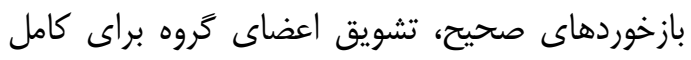
كردن درمان مديريت خشم، درباره مديريت خشمه هيه

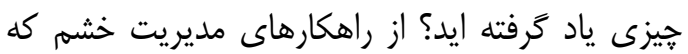

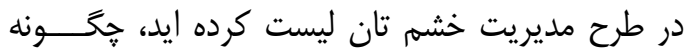

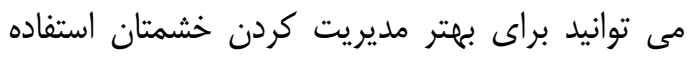
كنيد؟ حوزه هاى خاصى وجود دارد كه نياز بهاي بهن بهيبود

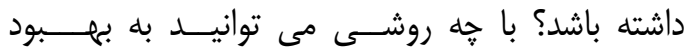
مهارت هاى مديريت خشم تان ادامه دهيد؟ تواني

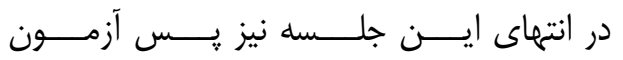

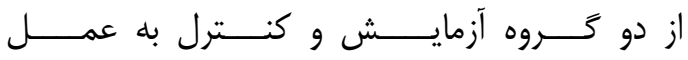

در اين يزوهش در خصوص آمار توصيفى از محاسبه ميانگين و انحر اف معيار، حداقل و حداكثر نمره

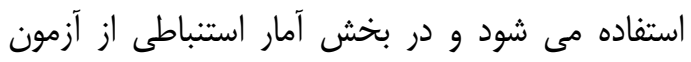

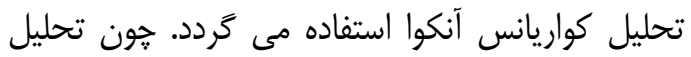
كواريانس اثر متغيرهاى مداخله گر را به روش هاى

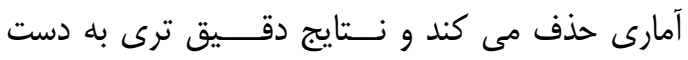
مى دهد.
شركت كنندًان درخواست مى شود، وقايع ويزه اي كه برانخيزنده خشمشان است را ليست كنند. جلسه سوم: دستورالعمل هايى براى افراد شركت كننده، روش وارسى، طرح هاى كنترل خشه، آرامش بخشى از طريق تنفس، تكاليف خانكى. جلسه جهارم: نكات مطرح شده در اين جلسه:

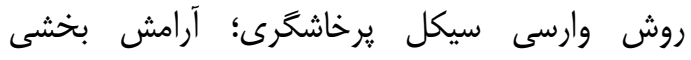
A-B-C- يشرونده عضلانى، بازسازى شناختى: مدل D توقف فكر و تكليف خانه.

جلسه بنجهز: در اين جلسه پِ خانكى جلسه قبل، روش درون وارسى توضيح داده شد دان

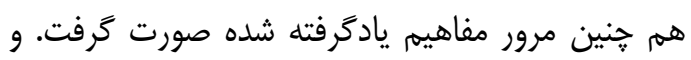

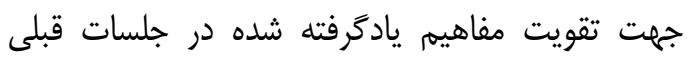

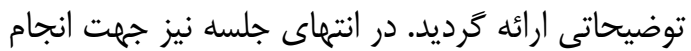
تكاليف خانه مباحثى مطرح شد. جلسه ششه; مباحث مطرح شده در اين جلسه

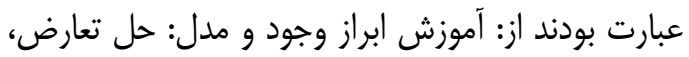

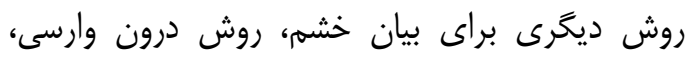

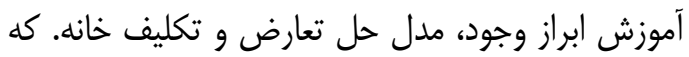

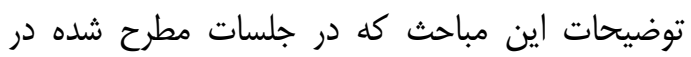

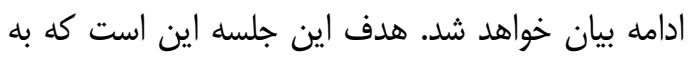

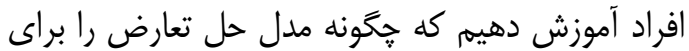

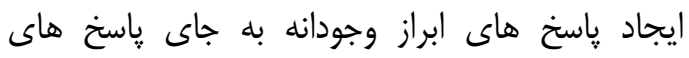
يرخاشگر انه و منفعلانه به كار برند. جلسه هشتهز: اقدامات انجام شده در اين جلسه عبارت بودند از: روش وارسى، بررسى و مرور نكات مطرح شده، خشم و خانواده و تكليف خانه. هدف اين

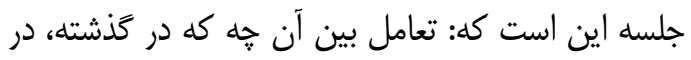

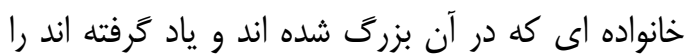

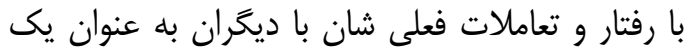

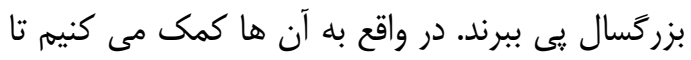

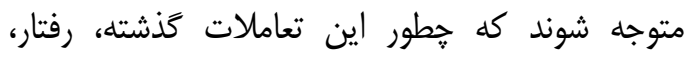
افكار، احساسات، نخرش هاى فعلى شان و شيوه تعاملى جنى كه در حال حاضر با ديخران برقرار مى كنند را تحت تاثير قرار داده است(بسيارى از مردم از ارتباط بين

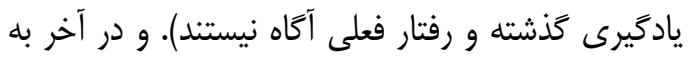
افراد كمى مى كنيم تا درك بهترى از خشمشان با كأن 
براى اطمينان از اين كه داده هاى اين بزوهش

يافته هاى يزوهش

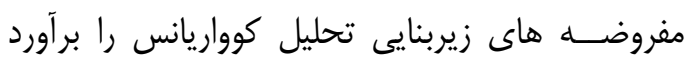

در اين مطالعه نتايج به دست آمده از دو گرَوه

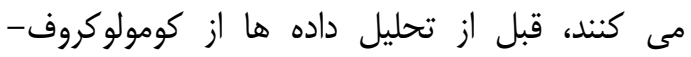
آزمايش و كنترل به صورت توصيفى و استباطى مورد

اسميرنوف براى نرمال بودن توزيع متغيرها در افراد

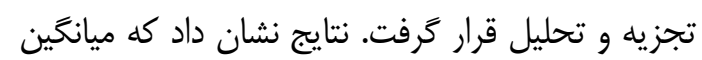

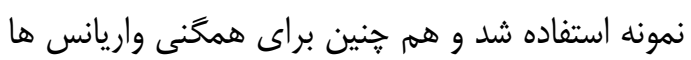

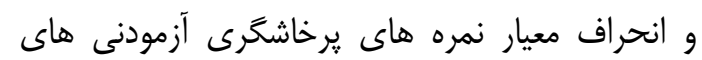

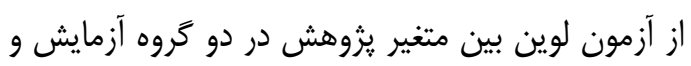

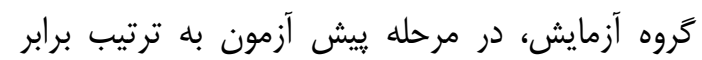
كنترل استفاده شد.

بر اساس نتايج حاصل از جدول شماره ا بين

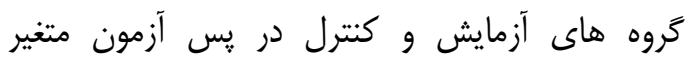

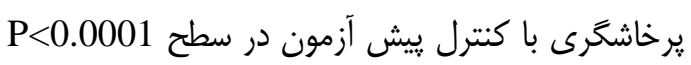

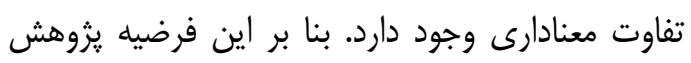

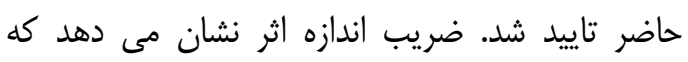

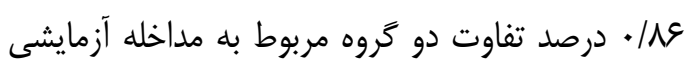

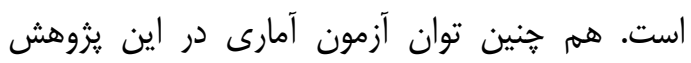

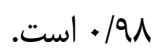

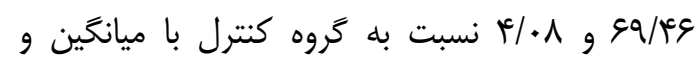

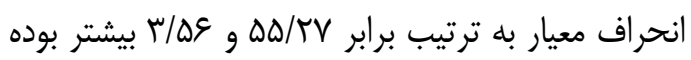

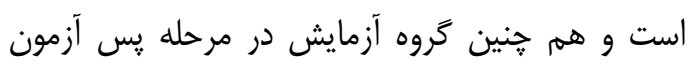

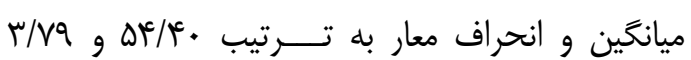

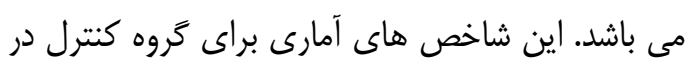

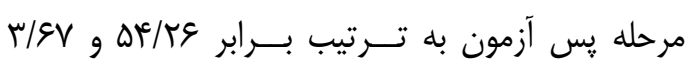

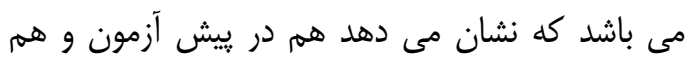

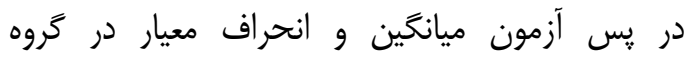
آزمايشى بيشتر از كروه كنترل بوده است.

\begin{tabular}{|c|c|c|c|c|c|c|c|c|}
\hline توان آزمون & اندازه اثر & سط بط معنادارى آزموز & F & ميانكين مجذورات روى ميات & درجه آزادى ازليل & 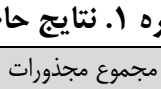 & منبع تغييرات & متغير \\
\hline$\cdot 1 \cdot V$ &.$/ \cdots 1$ & .190 & $\cdot / r \cdot \Delta$ & $r / \mu q$ & 1 & T/ץ & ييش آزمون &.${ }^{2 *}$ \\
\hline \multirow[t]{2}{*}{.$/ 91$} &.$/ N E$ &. $\mid \cdots \cdot$ & $\mid 90 / 91$ & $|N| r / \cdot 9$ & 1 & $|M| Y / \cdot r$ & كروه & iv \\
\hline & & & & $11 / \Delta F$ & rq & $r . . / / V$ & خطا & $y^{3}$ \\
\hline
\end{tabular}

كاهش آن ها شده اســـت. بــنـا بر اين تمام خرده

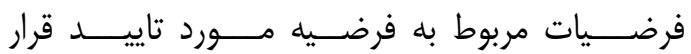
مى كيرند.
نتايج جدول شماره r نشان مى دهد كه آموزش

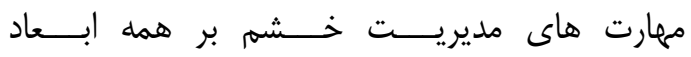

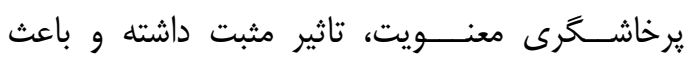

جدول شماره ז. نتايج حاصل از تحليل آنكوا بر روى ميانَين نمره هاى يس آزمون ابعاد يرخاشكَىى

\begin{tabular}{|c|c|c|c|c|c|c|}
\hline سطح معنادارى & $F$ & ميانكين مجذورات & درجه آزادى & مجموع مجذورات & خرده مقياس ها & متغير \\
\hline $.1 \cdot 1$ & $\pi / r q$ & $\mid r / T V$ & 1 & $1 \pi / T V$ & رفتار بِرخاشكَرانه & \\
\hline $.1 \cdot+1$ & $v / r q$ & $|\varepsilon / \pi|$ & 1 & $|s / r|$ & افكار بِرخاشكَرانه & \\
\hline . & 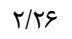 & W/AT & 1 & IVI & احساسات برخاشگَرانه & \\
\hline
\end{tabular}

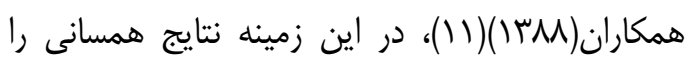

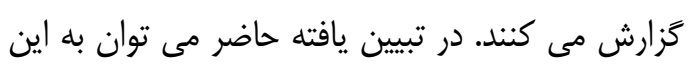

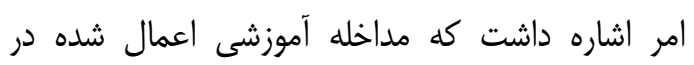

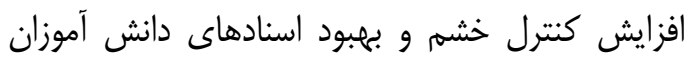

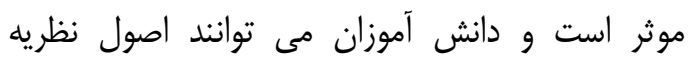

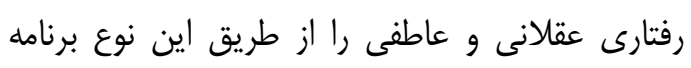

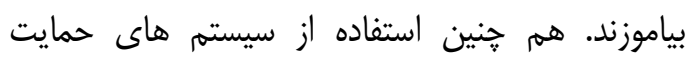

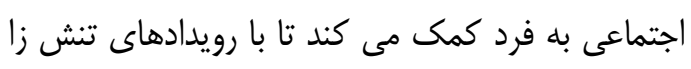
مقابله كند. سيستم حمايتى فرد شامل افرادى است كه فه

\section{بحث و نتيجه كَيرى}

هدف از يزوهش حاضر بررسى اثربخشى آموزش

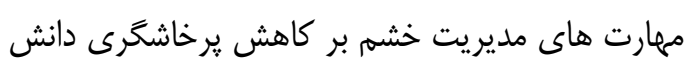

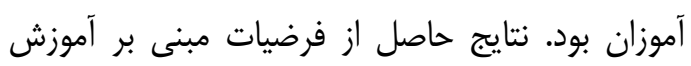

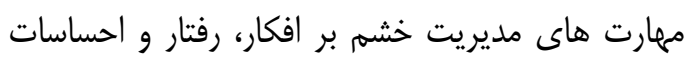

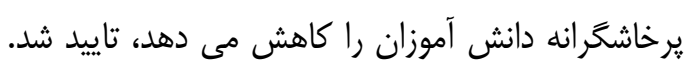

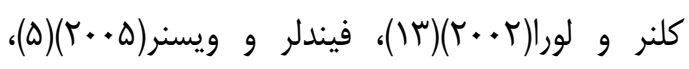

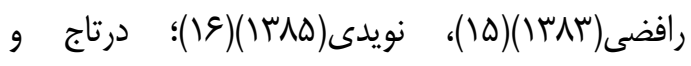


با اضطراب و مخاطرات طبيعى كاربرد زيادى داشته و در طول تاريخ حافظ بقاى نسل آدمى بوده است. ولى إنى

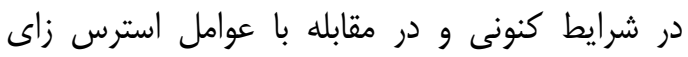

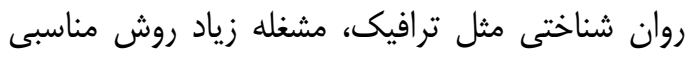

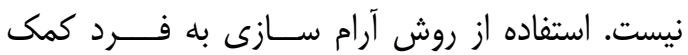

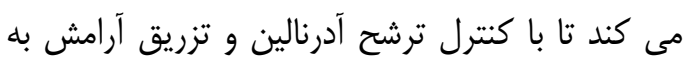

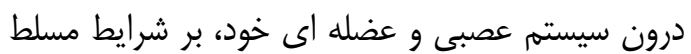

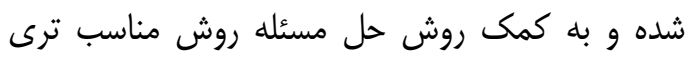

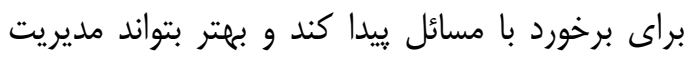
هيجانات منفى را در خود تقويت كند. هم خُنين وقتى بردي

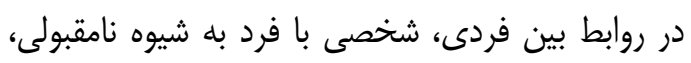

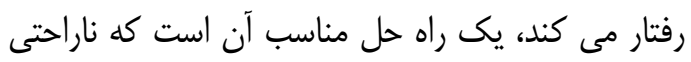

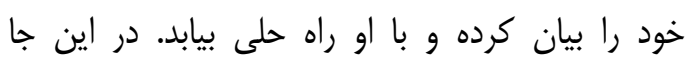
مهارت هاى جرات ورزى مى تواند ســـودمند باشد. جرات ورزى به معناى صريح و روراست بودن است نورن نه

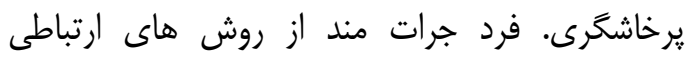

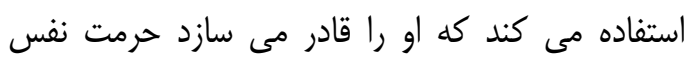

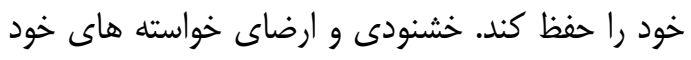

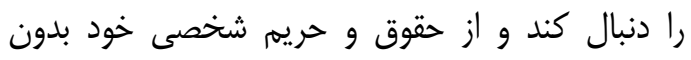

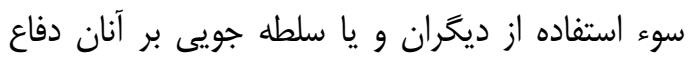
كند. كه اين امر منجر مى شود فرد با داشتن اين

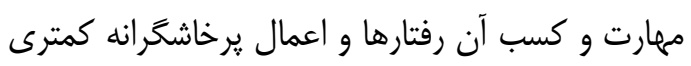
را از خود بروز دهد. لذا به طور كلى مى توان بوان بيان داشت يكى از روش هاى مناسب براى ييشخيرى از

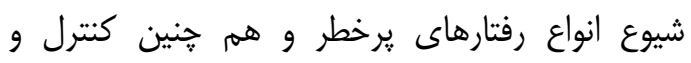

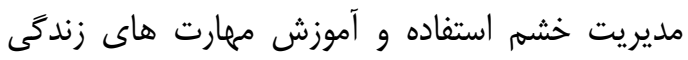

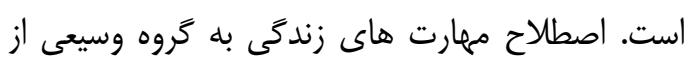

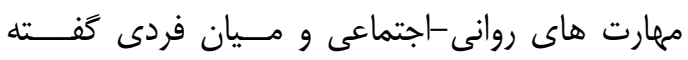

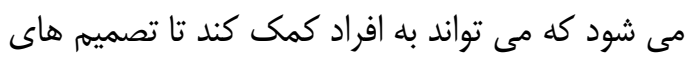

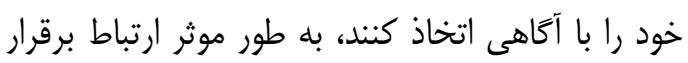

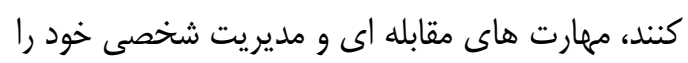

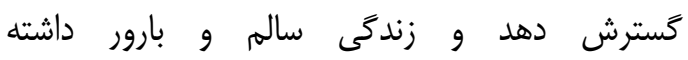

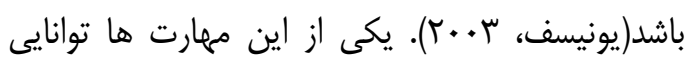

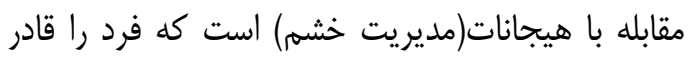

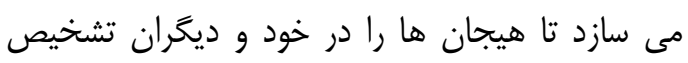

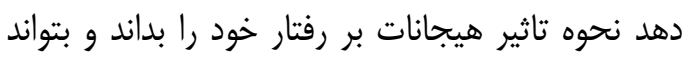
واكنش مناسبى به هيجان هاى مختلف نشان دهد(م).

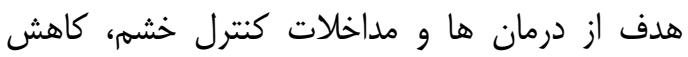

در شرايط سختى مى تواند روى آن ها حساب كند.

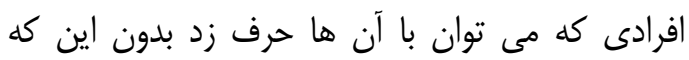

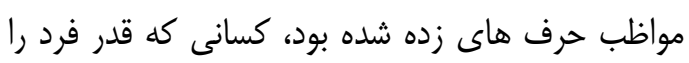

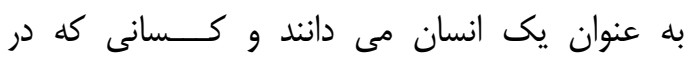
تصميم كيرى هاى مهرم به او كمك مى كن كنند. كه

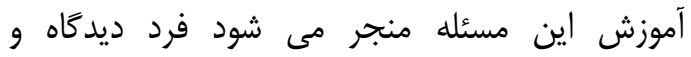

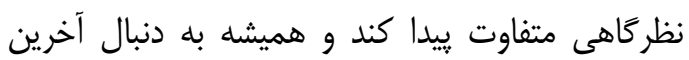

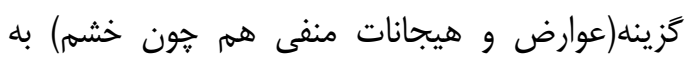

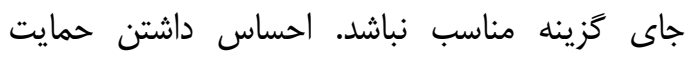

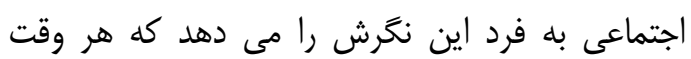

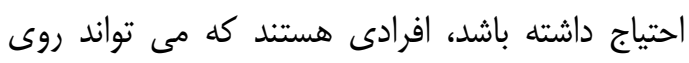

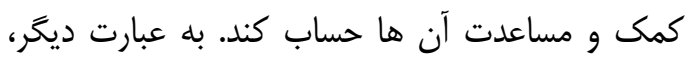

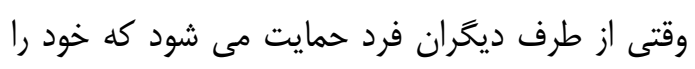
فردى مطلوب، مفيد، دوست داشتنى و و ارزشمند

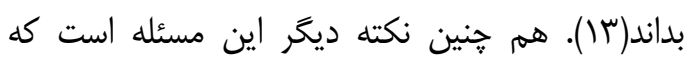

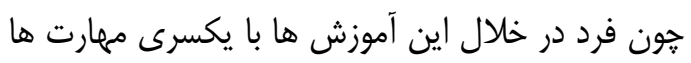
آشنا مى شود كه مربوط به اصلاح نظام شناختى فرد،

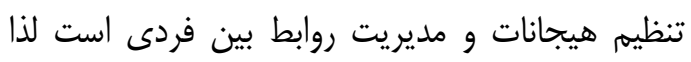

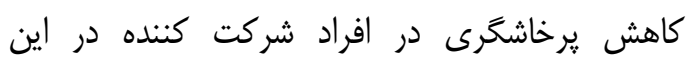

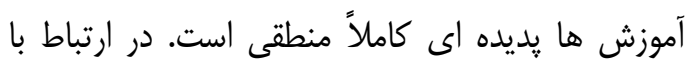

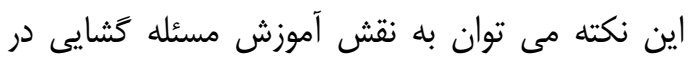

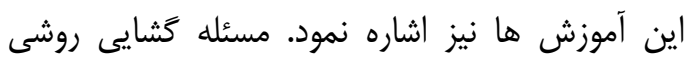

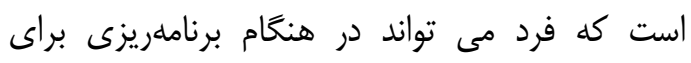
برخورد با مسايل زندكى از آن استفاده كند. استفاده از

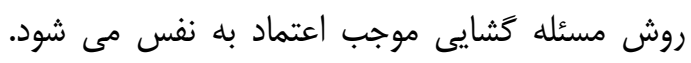

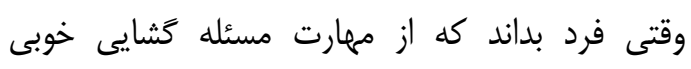
برخوردار است، احساس شايستخى و تسلط در او تقويت مى شود و شكل دهنده بسيارى از اعمال و رفتارهايش مى شود كه يِيامد آن مى تواند مسئله كاهش رهند رفتارهاى

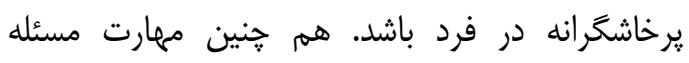

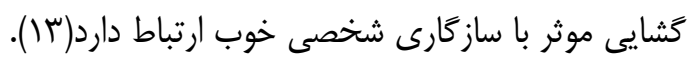

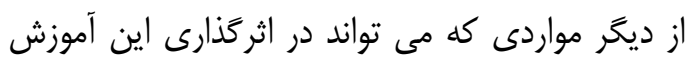

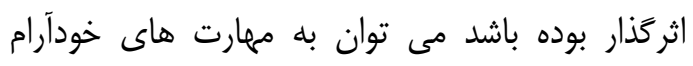

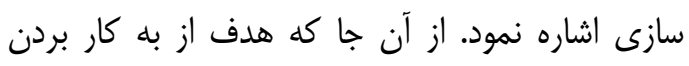

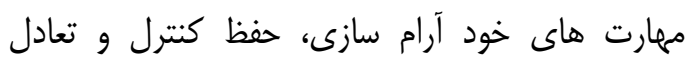

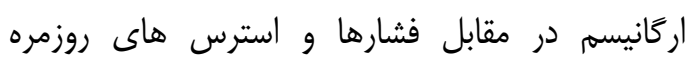

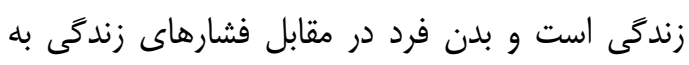

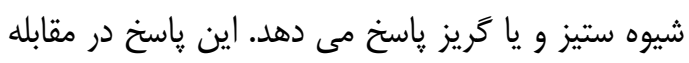




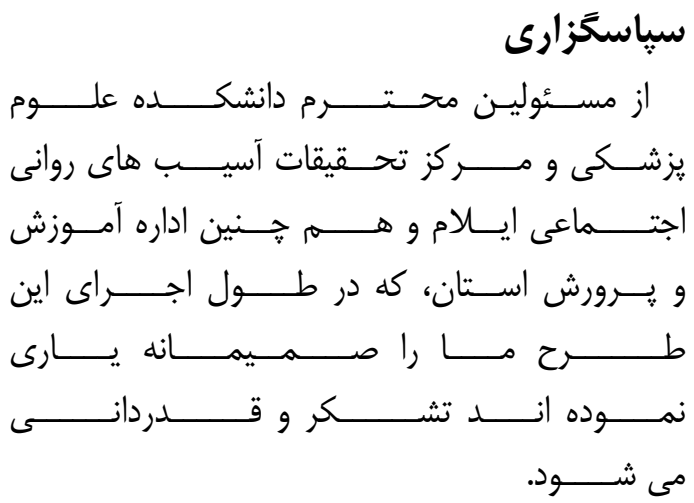

\section{References}

1. Delvecchio H, Olivery M. Effectiveness of anger treatment for specific anger problem. A meta-analytic review. J Clin Psychol2005; 2: 34-15.

2. Jons D. Managing problematic anger the development of treatment program for personality disordered patient in high security .Int J Forensic Ment Health2004; 3: 197-210.

3. Thomas S. Teaching healthy anger management. Pers Psychiatr Care2001; 37: 48-41.

4. Ghamarigivi H, Harafitisobhani R, Zahid A. [The effectiveness of cognitive behavioral therapy on the aggression of physically affected children]. Ravan Pouyesh2010; 1: 41-27. (Persian)

5. Feindler E, Weisner S. Youth anger management treatments for school violence prevention. J Fam Viol2005; 4: 26-38.

6. Shakibaei F, Tehranidoost M, Shahrivar $\mathrm{Z}$, Asari SH. Anger management group therapy with cognitive behavioral approach in institutionalized adolescents. New Cogn Sci2004; 6: 59-66.

7. Unicef. Which skills are life skills? Life Skills Based Edu Publication. 2003.

8. Aghabakhshi H. Life skills for students. Tehran Soc Plan Stud Min Sci Res Technol Publication. 2009; P.1-32.

9. Turgay A. Aggression and disruptive behavior disorder in children and adolscents. Exp Rev Neurol2004; 4: 62332.

$$
\begin{aligned}
& \text { احساسات هيجانى و برانخيختخى فيزيولوزيكى ناشى از }
\end{aligned}
$$

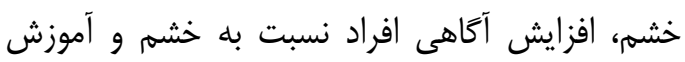

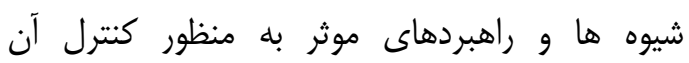

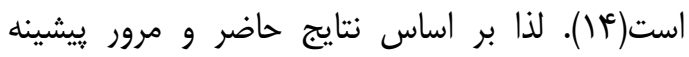

$$
\begin{aligned}
& \text { تجربى حول موضوع حاضر مى توان بيان داشت كه }
\end{aligned}
$$

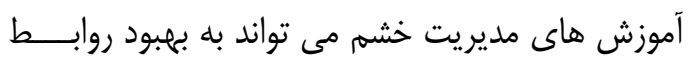

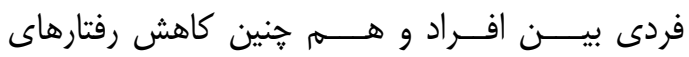

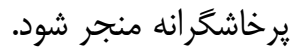

10. Arefi M, Razavieh A. Investigating the relationship between apparent aggression and the Relationship between social emotional compatibility of elementary male and female students. J Knowl Res Psychol Isfahan Uni Technol2006; 13: 113125.

11. Dartage F, Masaebei A, Asadzadeh $\mathrm{H}$. The effect of anger management training on aggression and social adjustment of 12-15 years old male students. Quart J Appl Psychol 2009; 3: 62-72.

12. Maleki S. The effect of group training on anger control skill on aggression among adolescents in middle schools in Karaj $2^{\text {nd }}$ district. Master's Thesis Nurs Serv Manage Tehran Tarbiat Modares Uni 2006.

13. Kellner M, Bry B, Colletti L. Teaching anger management skills to student with severe disorder. J Behavior Disorders2002; 4: 427-60.

14. Black L, Novaco R. Treatment of anger with a developmentally disabled man. NewYork Plenum Publication. 1993; P.143-58.

15. Rafezei Z. The effect of anger control training on aggression in adolescents aged 15 to 18 years old in Tehrans high schools. Master's Thesis Clin Psychol Uni Soc Welf Rehabil Sci Tehran2004.

16. Navidi A. The effect of anger management training on male selfregulatory skills adaptability and general health of at Tehran's high schools. J Iran Psychiatr Clin Psychol2008; 14: 394-401. 


\title{
Effectiveness of Teaching Management Skills on Aggression among Third Grade High School Boy-students in Ilam City (western Iran)
}

\author{
Bahamin $G^{l}$, Zarghamihajabi $M^{2 *}$, Mohebbi $M^{2}$
}

(Received: April 24, 2017

Accepted: January 30, 2018)

\begin{abstract}
Introduction: This study aims to investigate effectiveness of teaching management skills on decreasing aggression among third grade high school boy-students in Ilam city.

Materials \& Methods: This is a semiexperimental study with an unequal control group design. The statistical population of this study consisted of all the high school boy-students in Ilam city (western Iran). In our research, the Ahvaz's aggression questionnaire was used to determine the aggression level among the participants. A total of 40 students were chosen using multistage cluster sampling. In order to assign individuals to the groups, 30 students with high aggressiveness score were selected and randomly assigned to two experimental and control groups. Then, the experimental group participated in a cognitive-behavioral aggression management training course for 10 sessions
\end{abstract}

of 90 minutes; however, the control group did not receive any training.

Findings: The results indicated that teaching aggression management skills was effective in reducing aggression. There was a significant difference between the experimental and control groups in the posttest scores for the aggression variable with the pre-test control scores at $\mathrm{P}<0.0001$ level.

Discussion \& Conclusions: Our findings suggest that aggression management training is effective in promoting aggression control and improving students' helpful attributions; thus, the students can learn the principles of rational and emotional behavior theory through such a program.

Keywords: aggression management skills, improvement, boy-students, high school

1. Dept of Psychology, Faculty of Psychology, Payam-e-Nour University, Tehran, Iran

2. Dept of Psychology, Faculty of Psychology, Islamic Azad University, Qom, Iran

*Corresponding author Email: psychologyclinical993@yahoo.com 